\title{
Local Structural Changes during Martensite Decomposition in Cr-Mo Steel Dissimilar Weldments
}

\author{
Extreme lattice parameter changes in the soft zone led to the presence of \\ a ferrite band, indicating lower hardness
}

BY S. PETCHSANG, I. PHUNG-ON, J. SRITHORN, AND P. KIDKHUNTHOD

\begin{abstract}
The presence of a soft zone near the weld interface resulted from the martensite decomposition in the 2.25Cr-1Mo heat-affected zone (HAZ) of a Cr-Mo dissimilar joint during postweld heat treatment (PWHT). In this study, ER90S-B9 filler metal was deposited on 2.25Cr-1Mo (T22) base material and various PWHT durations were applied to investigate the changes in the local structures. Microstructural observations revealed the soft zone formation in the T22 HAZ close to the weld interface. During short PWHT durations, lattice parameters were slightly reduced. The T22 HAZ remained as a martensite structure. The transition period from martensite to ferrite was initiated after $2 \mathrm{~h}$ of PWHT. Extreme lattice parameter changes in the soft zone resulted from martensite decomposition and led to the presence of a ferrite band, indicating lower hardness. The decomposition of martensite to ferrite was completed after $4 \mathrm{~h}$ of PWHT. From the results, an attempt to apply the $x$-ray diffraction (XRD) technique was insufficient for differentiating the small changes in local structures. Therefore, the extended $x$-ray absorption fine structure (EXAFS) technique was introduced to give better analyzed data in terms of $\mathrm{r}$ space.
\end{abstract}

\section{KEYWORDS}

- Soft Zone - Martensite Decomposition

- Postweld Heat Treatment (PWHT) • Local Structure

- X-Ray Diffraction (XRD) • Extended X-Ray Absorption Fine Structure (EXAFS) $\bullet$ R-Space

\section{Introduction}

Dissimilar weld joints between different grades of lowalloy ferritic steels are essential for the fabrication and repair of piping or tubing in power plants, especially between low- $\mathrm{Cr}$ and high- $\mathrm{Cr}$ ferritic steels (Refs. 1-5). Postweld heat treatment (PWHT) must be employed on Cr-Mo steel dis- similar joints. Complex metallurgical structures can be observed at the weld interface (Refs. 4, 6, 7). Previous investigations have reported the presence of "soft" and "hard" zones along the weld interface during PWHT. The martensite structure in the heat-affected zone (HAZ) transferred to the ferrite phase resulting in low hardness (Refs. 1, 2, 7-16).

Many in the literature have studied the soft zone formation in dissimilar $\mathrm{Cr}$-Mo weldments by observing metallographic information (Refs. 1, 2, 8, 10, 13-16). However, no investigations determined the microstructural transformation of this zone during PWHT in terms of the local structural changes. Studying the local structural changes of phases could be helpful for identifying the decomposition of martensite to ferrite. Changes in lattice parameters could be performed using x-ray diffraction (XRD), which provided considerable resolution due to its nature in phase-selective technique. For better resolution, extended $\mathrm{x}$-ray absorption fine structure (EXAFS) could be conducted for its element-selective technique. The combination of both techniques could provide a complementary structure view of microstructural transformation (Refs. 17-24).

This paper investigates the local structure changes with different PWHT durations in the soft zone of a dissimilar joint between $2.25 \mathrm{Cr}$-1Mo steel (ASTM SA213 grade T22) and ER90S-B9 filler metal (overmatching to T22 steel) by employing XRD and EXAFS methods. Results obtained from both techniques will be helpful as a baseline for further determination of the microstructural transition mechanism in Cr-Mo steel dissimilar joints.

\section{Experimental Procedures}

\section{Materials and Welding Procedure}

The material used as the base metal (BM) for the dissimilar weld preparation was $2.25 \mathrm{Cr}$-1Mo steel seamless tube (ASTM SA213 grade T22) in the as-received condition with dimensions $50.8 \mathrm{~mm}(\mathrm{OD}) \times 2.7 \mathrm{~mm}$ (wall thickness) $\times 25.0 \mathrm{~mm}$ 

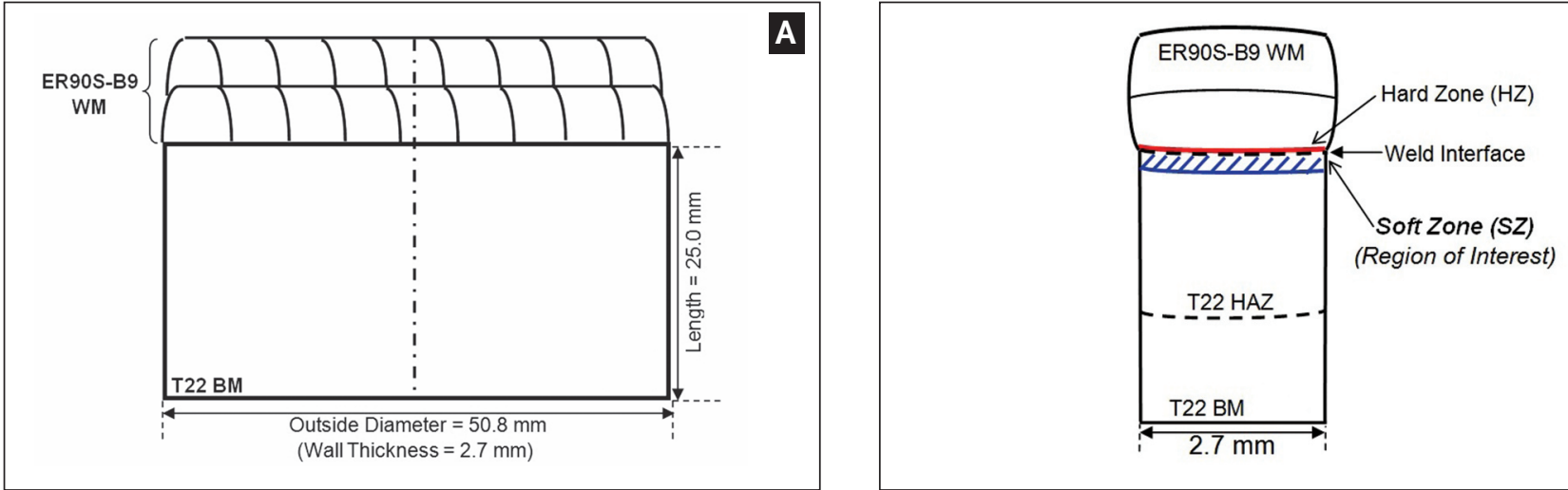

Fig. 1 - Welded specimen preparation: A - Side view; B - front view.

(length). The ER90S-B9 filler metal was fabricated on the cross-section circumferentially for two layers as the B9/T22 weld using the gas tungsten arc welding (GTAW) process, as shown in Fig. 1. The nominal and measured compositions of the base metal and the deposited weld metal (WM) are listed in Table 1. Details of the welding parameters used followed the ASME qualified Welding Procedure Specification (WPS) as shown in Table 2. After welding, the welded joint was cut for PWHT performed at $760^{\circ} \mathrm{C}$ (conformed to minimum PWHT required by the ASME code) for various time durations (aswelded, 0.5, 1, 2, 4, and 8 h), as shown in Fig. 1.

\section{Metallurgical Preparation and Microhardness}

Microstructural examination at the weld interface of the dissimilar joints, especially in the soft zone, was performed using optical microscopy (OM). The welded joints were polished and etched using $10 \mathrm{~mL} \mathrm{HNO}_{3}+20 \mathrm{~mL} \mathrm{HCl}+30 \mathrm{~mL}$ water for $90 \mathrm{~s}$ to show the general structure and $5 \mathrm{~g} \mathrm{FeCl}_{3}+5$ drops $\mathrm{HCl}$

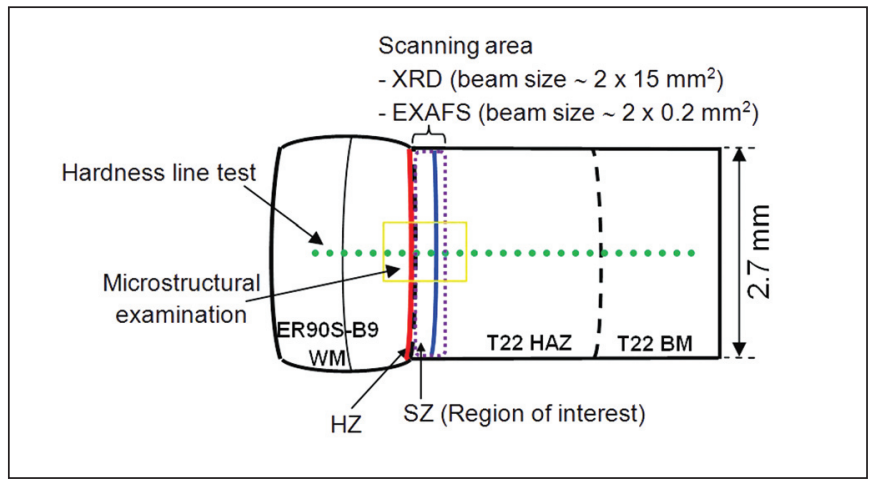

Fig. 2 - Outline of the dissimilar weldment with region of interest.

$+100 \mathrm{~mL}$ water for $10 \mathrm{~s}$ to show the prior austenite grain boundaries, according to the ASTM E407 standard (Ref. 27).

The hardness of the base metal and all weldment subzones

Table 1-Chemical Compositions of the Base Metal and the Deposited Weld Metal

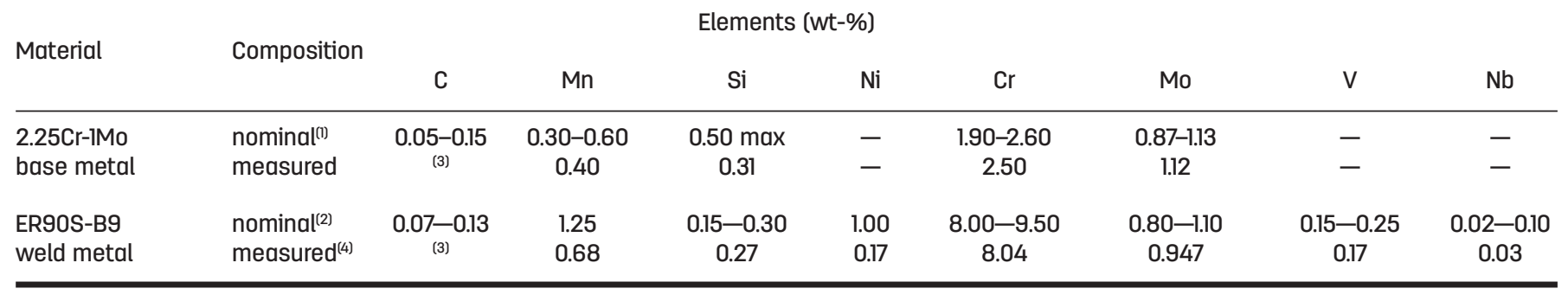

1. Refer to (Ref. 25)

2. Refer to (Ref. 26)

3. Not determined

4. Measured in the weld metal by SEM/EDS analysis.

Table 2 - Welding Parameters

\begin{tabular}{|c|c|c|c|c|c|c|c|}
\hline Configuration & Layer no. & \multicolumn{2}{|c|}{ Filler Metal } & Polarity & $\begin{array}{l}\text { Current } \\
\text { (A) }\end{array}$ & $\begin{array}{l}\text { Voltage } \\
\text { (V) }\end{array}$ & $\begin{array}{l}\text { Travel Speed } \\
\text { (cm/min) }\end{array}$ \\
\hline \multirow[t]{2}{*}{ B9/T22 } & 1 & ER90S-B9 & 2.4 & DCEN & 60 & $11-12$ & 13.3 \\
\hline & 2 & ER90S-B9 & 24 & DCEN & 60 & 1]-12 & 116 \\
\hline
\end{tabular}




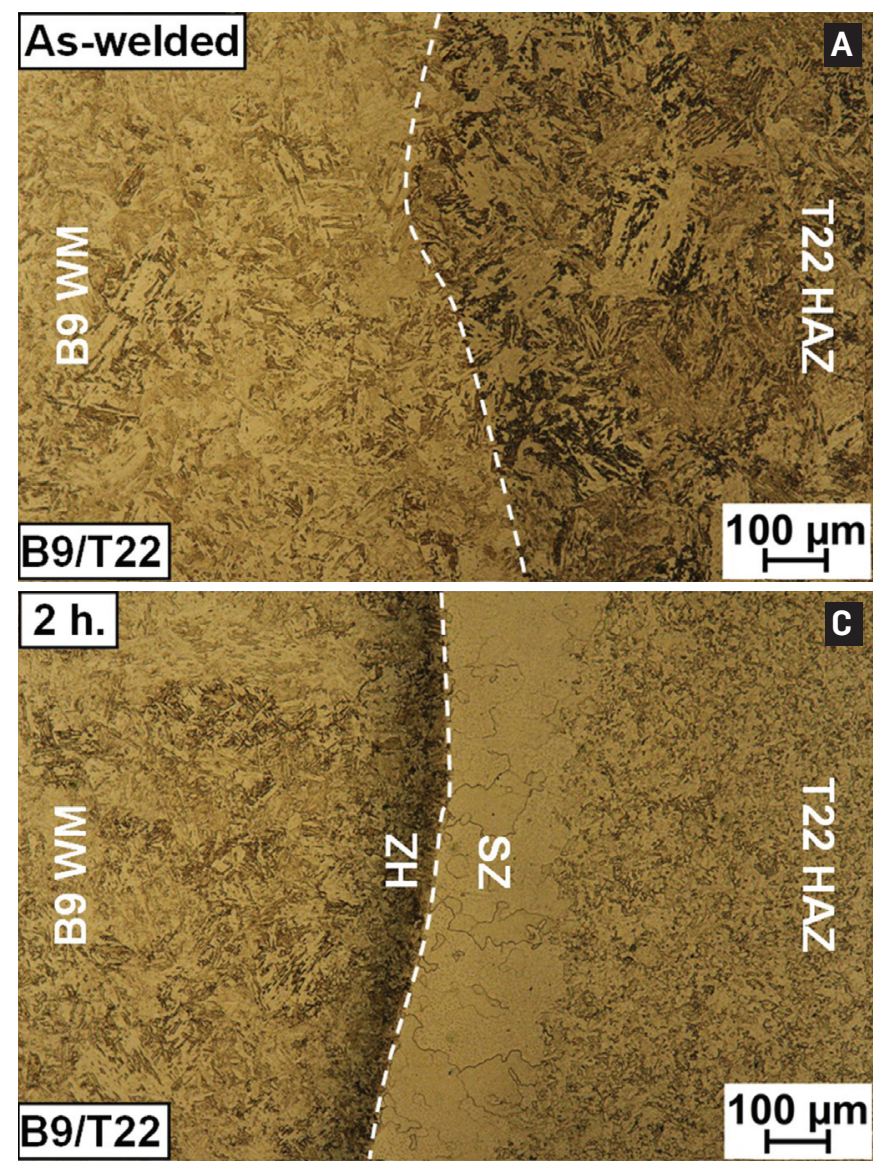

Fig. 3-OM micrographs at the B9/T22 weld interface after PWHT at $760^{\circ} \mathrm{C}$ for the following: $A-A s$-welded; $B-1 \mathrm{~h} ; \mathrm{C}-$ $2 h$; $D-4 h$; $E-8 h$. SZ refers to the soft zone, $H Z$ the hard zone, HAZ the heat-affected zone, and WM the weld metal.

was measured using a Vickers microhardness tester with a load of $200 \mathrm{gf}$ and a loading time of $10 \mathrm{~s}$ on points equidistant at 250 microns across the weld interface. Figure 2 presents a schematic of the region of interest in the weldment for microstructural observations and microhardness measurements.

\section{XRD Measurement}

The XRD analysis was performed on a Bruker D8 Discover diffractometer with $\mathrm{Cu} \mathrm{K}$ radiation $(\lambda=1.54 \AA)$. This technique was carried out on the T22 HAZ adjacent to the weld interface with different PWHT durations (Fig. 2) to analyze the change in crystal structure of each sample in terms of lattice parameters, diffraction angle, and d-spacing.

\section{EXAFS Technique}

To address the oxidation states of the metal atoms and the local environment around these ions at different sample conditions, EXAFS spectra at the Fe K-edge were conducted at beamline 5.2 (XAS) (Refs. 28, 29) (electron energy of $1.2 \mathrm{GeV}$, bending magnet, beam current $80-150 \mathrm{~mA}, 1.1$ to $1.7 \times 10^{11}$ photon $\mathrm{s}^{-1}$ ) at the Synchrotron Light Research Institute (SLRI), Nakhon Ratchasima, Thailand. All spectra were measured in the fluorescence mode with four-element silicon drift detector. For the acquisition of all spectra, a Ge (220) double crystal

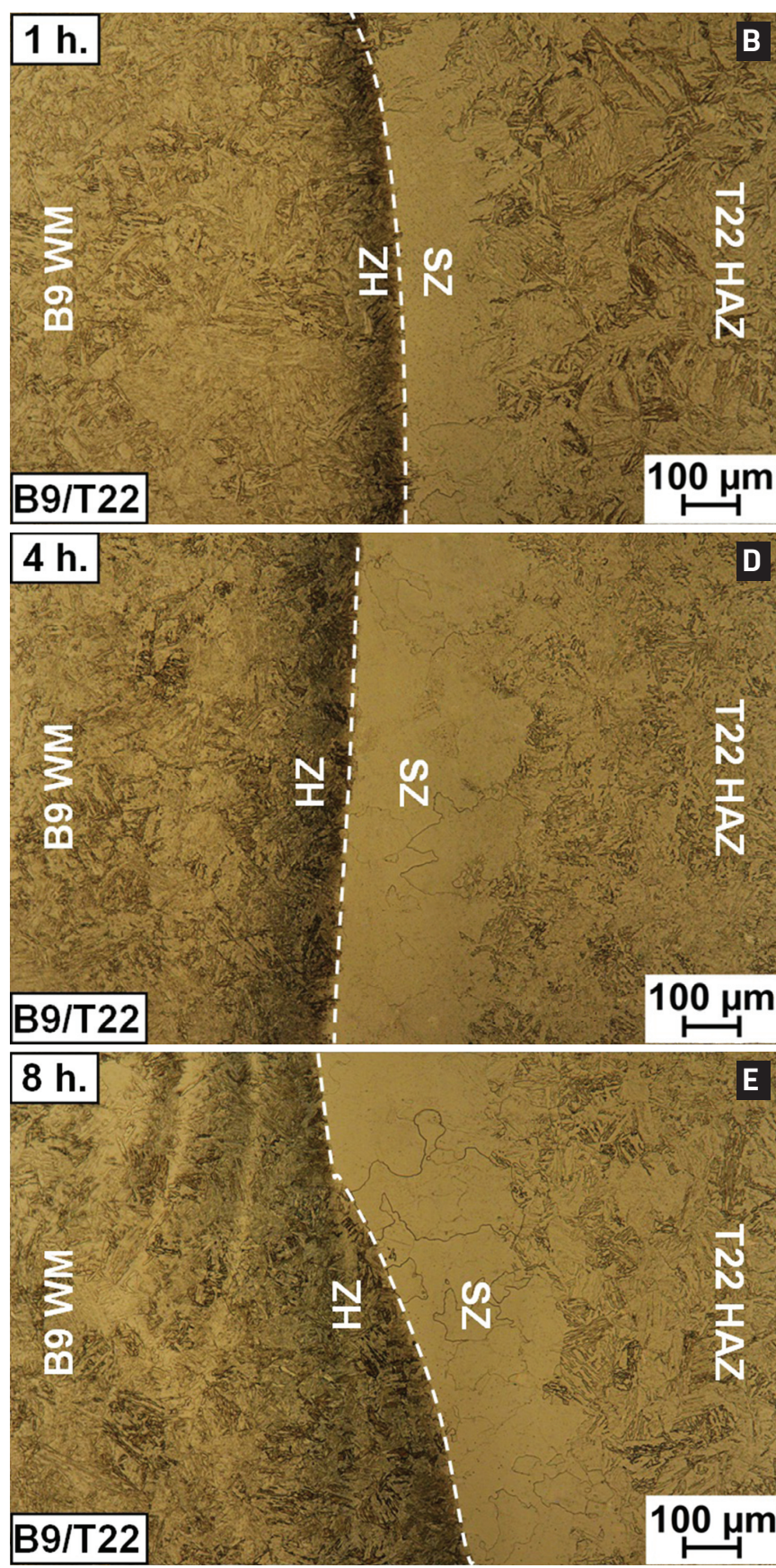

monochromator with an energy resolution $(\Delta \mathrm{E} / \mathrm{E})$ of $2 \times 10^{-4}$ was used to scan the synchrotron $\mathrm{x}$-ray beam. Normalized XAS data were processed and analyzed after background subtraction in the pre-edge and post-edge region using ATHENA software included in an IFEFFIT package (Refs. 30, 31). This method was also conducted in the T22 HAZ where the soft zone occurred, as shown in Fig. 2.

\section{Results and Discussion}

\section{Microstructural Evaluation and Microhardness}

Figure 3A-E shows optical micrographs along the weld interface of the welded specimens with different PWHT durations. In the as-welded sample (Fig. 3A), the T22 HAZ con- 


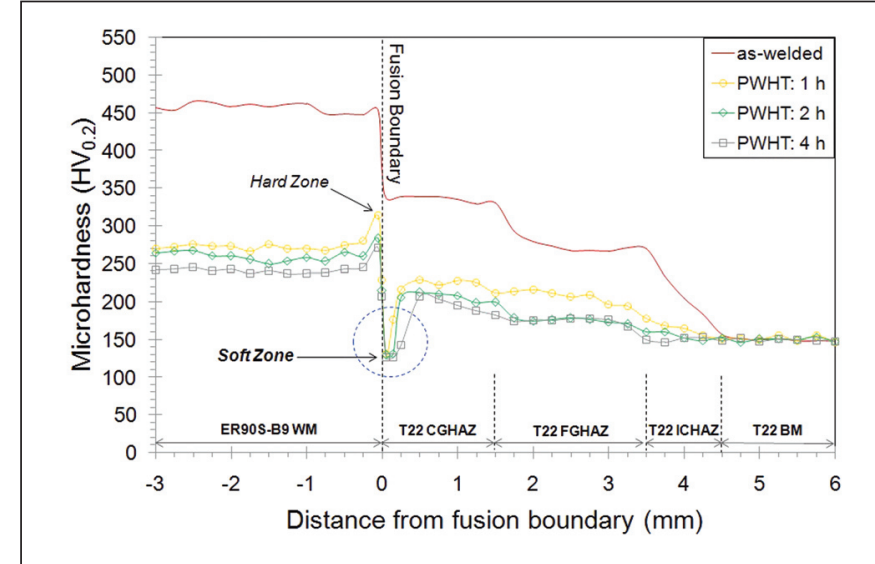

Fig. 4 - Microhardness profiles of the B9/T22 weldments with various $P W H T$ durations. WM refers to the weld metal, CGHAZ the coarse-grain heat-affected zone, FGHAZ the finegrain heat-affected zone, ICHAZ the intercritical heataffected zone, and BM the base metal.

tained martensite (Ref. 3) resulting from phase transformation mechanism during welding (from austenite $(\gamma)$ to martensite $\left(\alpha^{\prime}\right)$ structure). However, after PWHT for $1 \mathrm{~h}$, a soft zone and hard zone occurred at the T22 HAZ and ER90S-B9 weld metal (WM), respectively, across the weld interface - Fig. 3B. The soft zone was composed of a ferrite band while the hard zone contained a precipitate-rich band (Refs. 1, 7, 8, 14). In the soft zone, partial martensite transformed to ferrite $(\alpha)$ structure during PWHT (Ref. 2). The specimen with short PWHT duration would only post an incomplete decomposition of martensite. Longer PWHT durations resulted in a broader soft zone as a ferrite band - Fig. $3 \mathrm{C}-\mathrm{E}$. Further decomposition of martensite occurred with the formation of carbide along the grain boundaries of ferrite (product of martensite decomposition) (Refs. 1, 2).

The microstructural examination was in agreement with the microhardness profiles across the weldments, as shown in Fig. 4. From the fusion boundary toward the base metal, the hardness of the T22 HAZ in the as-welded condition was about $340 \mathrm{HV}_{0.2}$ corresponding to the martensite structure. Nevertheless, after PWHT, the lowest hardness (around 130 $\mathrm{HV}_{0.2}$ ) appeared in the T22 HAZ near the weld interface where the soft zone developed (Refs. 1, 2, 8). These results could confirm that the microstructural transformed from the martensite decomposition into ferrite grains. During PWHT, the martensite in the prior austenite grain began to decompose into ferrite structure with carbides at the grain boundaries (Refs. 32-34). As the PWHT times were increased, the larger ferrite grains were observed in the soft zones (Ref. 1).

\section{XRD Analysis}

The decomposition of martensite in the HAZ was determined by a change in the lattice parameters in terms of diffraction angle and the d-spacing of dissimilar welded samples with various PWHT times. The d-space or the interplanar distance $(\mathrm{d})$ value was obtained from the XRD measurement based on Bragg Equation $(\mathrm{n} \lambda=2 \mathrm{~d} \sin \theta)($ Refs. 35, 36). According to the equation, the larger diffraction angle, the
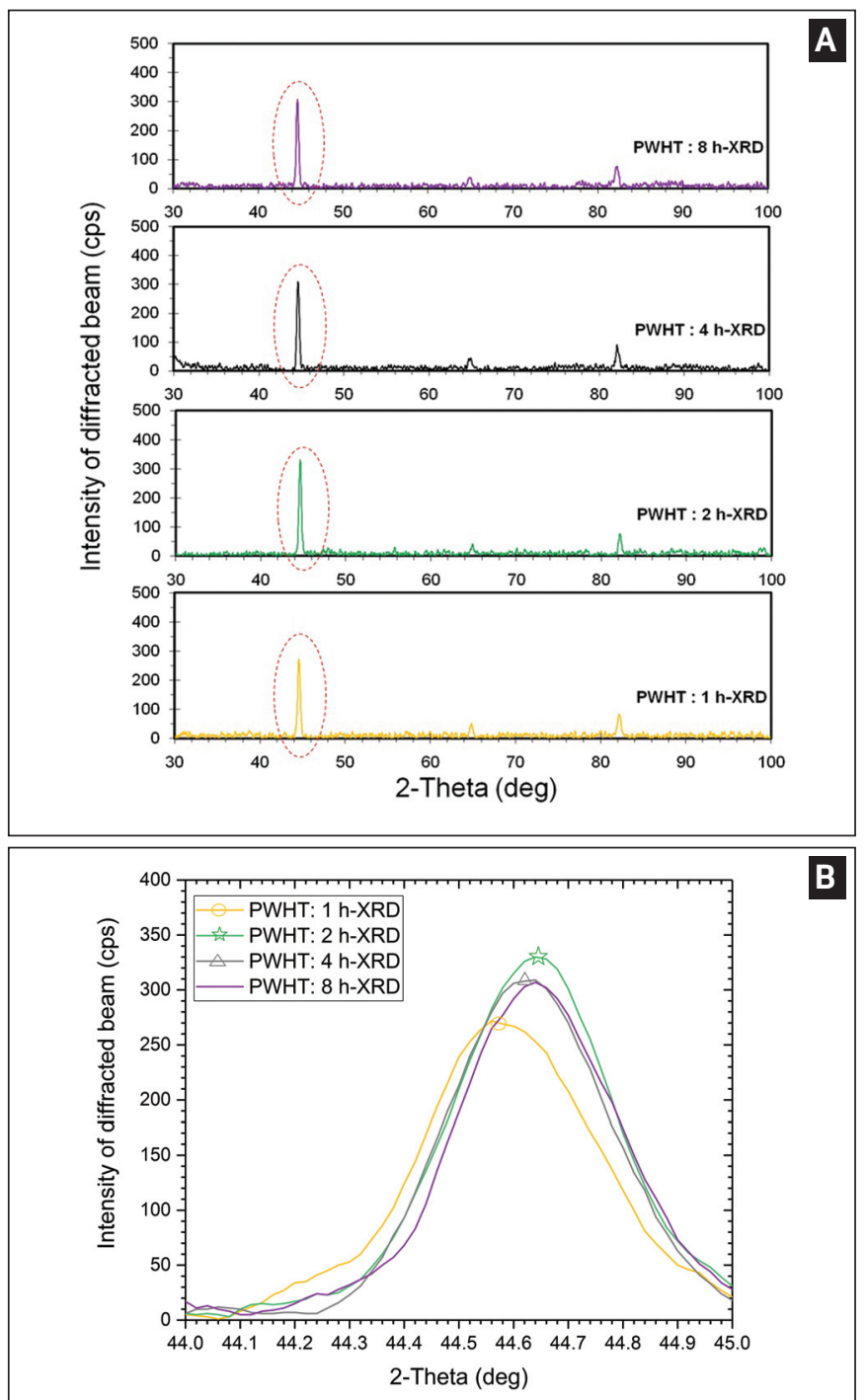

Fig. 5-A X XRD patterns; $B-$ the first diffraction peak of $X$ ray diffraction at $2 \theta$ for T22 HAZ (soft zone) of dissimilar joints with different PWHT durations.

lower d-spacing. Figure 5A shows an overview of the $\mathrm{x}$-ray diffraction pattern in the T22 HAZ (adjacent to the weld interface) of B9/T22 weldments. Figure 5B exhibits the first diffraction peak of $x$-ray diffraction at $2 \theta$ of each welded specimen.

From Fig. 5B, after PWHT for $1 \mathrm{~h}$, the diffraction angle was at $44.565 \mathrm{deg}$, which can be matched with those of the body-centered cubic (BCC) martensite structure from other research (Refs. 37-41) resulting from the carbon content of this steel lower than 0.6 wt-\% (Refs. 42-46). Only martensite was found, although this area was a mixture of martensite and ferrite structure from the microstructural observation. This is due to the fact the magnitude of the ferrite band contained was too small to be detected. The XRD results indicated the diffraction peaks changed with increasing PWHT times. The diffraction peak of the 2-h PWHT specimen shifted considerably to the higher value $(2 \theta=44.638$ deg) compared to the 1-h PWHT sample in which the interplanar distance reduced from 2.03151 to $2.02836 \AA$ as the 


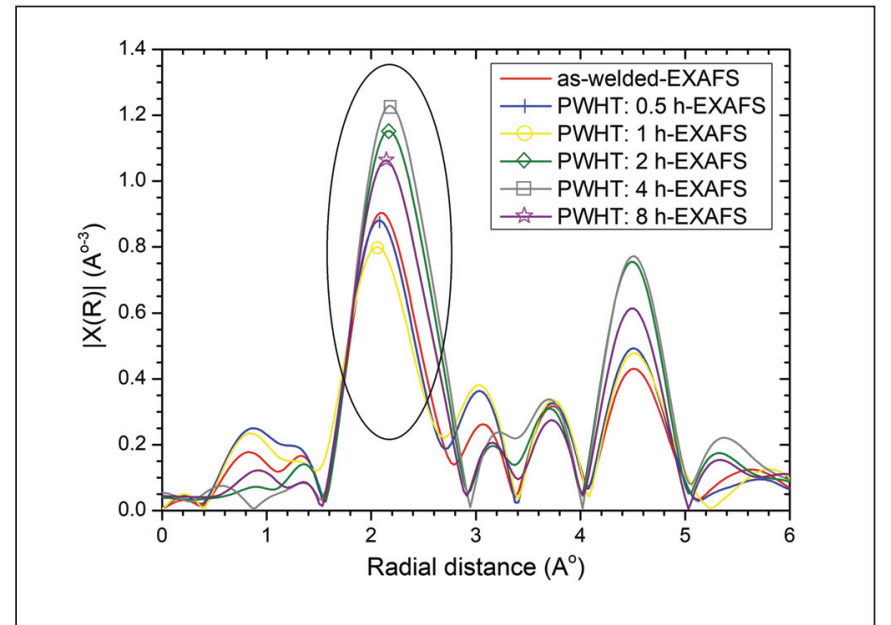

Fig. $6-R$-space in the soft zone of B9/T22 dissimilar joints with various $P W H T$ durations.

BCC martensite transformed to BCC ferrite (Refs. 39, 41, $47,48)$. With increasing PWHT time, carbon diffused from the iron lattice, which led to partial martensite decomposition in the T22 HAZ close to the weld interface (Ref. 41).

After PWHT for $4 \mathrm{~h}$, the diffraction peak shifted slightly to the left side $(2 \theta=44.628 \mathrm{deg})$ compared to the $2-\mathrm{h}$ PWHT sample and exhibited larger d-space $(d=2.02881 \AA$ ) resulting from increased martensite decomposition during PWHT and the presence of BCC ferrite phase in the T22 HAZ (soft zone). In addition, the diffraction peak of the 8-h PWHT sample shifted to the right side $(2 \theta=44.642 \mathrm{deg})$ compared to the 4-h PWHT specimen. The crystal structure remained BCC ferrite but with smaller $d$-space $(d=2.02821$ $\AA$ ). This might be due to the absence of interstitial carbon atoms in the iron lattice causing lower distortion of the BCC ferrite structure with longer PWHT durations (Refs. 49, 50).

However, it was difficult to distinguish between martensite and ferrite structures because the difference in lattice parameters (diffraction angle and interplanar distance) was very small (Refs. 39-41, 48, 51). Therefore, XAS measurement using the EXAFS technique was applied to compare data obtained from the XRD investigations.

\section{EXAFS Results}

Fourier transformed EXAFS of the Fe K-edge data (in fluorescence mode) was used to determine the change in lattice parameter in terms of the radial distance (interatomic distance; $r$-space) of the soft zone (T22 HAZ) resulting from the decomposition of martensite. Figure 6 presents EXAFS results of the soft zone in B9/T22 weldments with different PWHT durations.

The T22 HAZ close to the weld interface of the as-welded specimen was composed of a martensite structure. After PWHT for half an hour, the r-space shifted slightly to the left and with longer PWHT ( $1 \mathrm{~h})$, the $\mathrm{r}$-space also reduced from 2.0862139 to $2.0555343 \AA$. There was a little martensite decomposition in the T22 HAZ with short-time PWHT.

Nonetheless, when PWHT time was increased from 1 to 2 $\mathrm{h}$, the peak shifted to the higher value from 2.0555343 to $2.1782527 \AA$, indicating a larger $r$-space as the BCC marten-

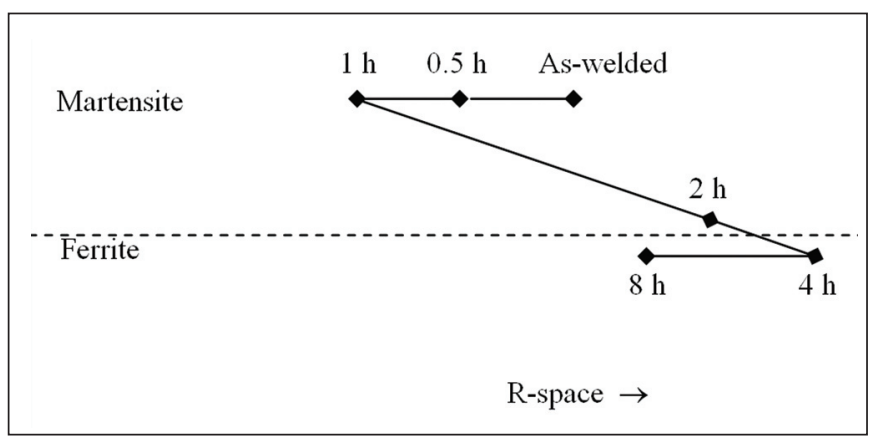

Fig. 7-The sequence of microstructural transition (martensite $\rightarrow$ ferrite) in the soft zone of the B9/T22 weldment with different PWHT durations in terms of r-space.

Table 3-Comparison of the XRD and EXAFS Results in T22 HAZ (soft zone) of Dissimilar Joints

Condition $2 \theta(\mathrm{XRD}) \quad$ R-space (EXAFS)

$\left.\begin{array}{lccl}\hline \text { As-welded } & \text { N/A } & \alpha^{\prime} & \\ \text { PWHT 0.5 h } & \text { N/A } & \alpha^{\prime} & \text { (smaller) } \\ \text { PWHT 1 h } & \alpha^{\prime} & \alpha^{\prime} & \text { (smaller) } \\ \text { PWHT 2 h } & \alpha^{\prime}+\alpha & \alpha^{\prime}+\alpha & \text { (larger) Transition Period } \\ \text { PWHT 4 h } & \alpha & \alpha & \text { (larger) } \\ \text { PWHT 8 h } & \alpha & \alpha & \text { (smaller) }\end{array}\right\}$.

site structure transformed to BCC ferrite phase and the BCC ferrite phase became prominent in the soft zone. The microstructural transition resulted from the partial decomposition of martensite during PWHT. With longer PWHT (4 h), the $r$-space increased slightly compared to the 2-h PWHT This was due to a complete decomposition of martensite to ferrite. However, the $r$-space of the 8 -h PWHT sample with ferrite phase showed a small decrease $(r$-space $=2.1475731$ $\AA$ ) compared to the 4-h PWHT specimen, resulting from no carbon trapped in the $\alpha$-Fe lattice during PWHT.

The EXAFS results presented here were consistent with those from XRD analysis. From Table 3, the T22 HAZ close to the weld interface of the as-welded sample was composed of BCC martensite as a result of phase transformation from austenite to martensite after welding. After short PWHT durations $(0.5$ and $1 \mathrm{~h})$, the martensite still remained in the T22 HAZ, but with smaller $r$-space. A slight martensite decomposition occurred during the short PWHT times.

The change in lattice spacing from BCC martensite to BCC ferrite in the T22 HAZ occurred after PWHT for $2 \mathrm{~h}$ (transition period), with a large change in $\mathrm{R}$-space resulting from partial martensite decomposition, which led to a mixed structure of martensite and ferrite; however, the ferrite could be distinguished. After PWHT for $4 \mathrm{~h}$, the microstructural transformation was completed with larger Rspace due to increased martensite decomposition. Moreover, the 8-h PWHT sample presented a smaller R-space due to lack of carbon occupied in the $\alpha$-ferrite with the increased PWHT durations. Figure 7 summarizes the sequence of soft zone formation in the dissimilar joints during PWHT.

The results were conformed to microstructural observations in terms of the sequence of transformation, which was not exact in PWHT duration. According to the microstructure, 
the ferrite band could be observed from 1-h PWHT. However, XRD and EXAFS analysis could still detect as martensite. This was due to the fact the beam size of EXAFS was larger than the size of the ferrite band presented. Therefore, the signals were acquired from both ferrite soft zone and decomposed martensite. For longer PWHT duration, the size of ferrite band was larger than the beam size. In this case, all the signals were acquired from the decomposed martensite.

\section{Conclusions}

Both XRD and EXAFS techniques were performed to investigate martensite decomposition at the weld interface of Cr-Mo dissimilar joints between T22 steel and ER90S-B9 filler metal using the GTAW process. Results were obtained as follows:

1) The formation of soft and hard zones was observed in the T22 HAZ and B9 WM adjacent to the weld interface during PWHT in Cr-Mo dissimilar joints.

2) The soft zone that occurred in the T22 HAZ was composed of a ferrite phase due to martensite decomposition indicating a lower hardness.

3) Both XRD and EXAFS results indicated the change in crystal structure from $\mathrm{BCC}$ martensite to $\mathrm{BCC}$ ferrite due to martensite decomposition in the soft zone began after PWHT for $2 \mathrm{~h}$. Nonetheless, the usage of EXAFS technique gave a better resolution compared to XRD analysis.

4) The transition period of martensite to ferrite in the T22 HAZ near the weld interface (soft zone) occurred after 2-h PWHT, with martensite decomposition and microstructural transformation completed after 4-h PWHT.

\section{Acknowledgments}

This research was supported by Asia Energy Engineering Co. Ltd., which supplied the material (T22 steel tube). The authors would like to thank Synchrotron Light Research Institute (Public Organization) beamline 5.2: SUT-NANOTEC-SLRI XAS beamline for the EXAFS measurements. The authors are grateful to Department of Mining and Materials Engineering and Center of Excellence in Materials Engineering (CEME), Prince of Songkla University, for research funding.

\section{References}

1. Sudha, C., Terrance, A. L. E., Albert, S. K., and Vijayalakshmi, M. 2002. Systematic study of formation of soft and hard zones in the dissimilar weldments of Cr-Mo steels. Journal of Nuclear Materials 302: 193-205. DOI: 10.1016/S0022-3115(02)00777-8

2. Albert, S. K., Gill, T. P. S., Tyagi, A. K., Mannan, S. L., Kulkarni, S. D., and Rodriguez, P. 1997. Soft zone formation in dissimilar welds between two Cr-Mo steels. Welding Journal 76(3): 135-s to 142-s.

3. Regev, M., Berger, S., and Weiss, B. Z. 1996. Investigation of microstructure mechanical and creep properties of weldments between T91 and T22 steels. Welding Journal 75(8): 261-s to 268-s.

4. Laha, K., Chadravathi, K. S., Rao, K. B. S., Mannan, S. L., and Sastry, D. H. 2001. An assessment of creep deformation and fracture behavior of $2.25 \mathrm{Cr}$-1Mo similar and dissimilar weld joints. Metallurgical and Materials Transactions A 32A: 115-124. DOI: 10.1007/s11661-001-0107-9
5. Mittal, R., and Sidhu, B. S. 2014. Microstructural and mechanical characterization of the different zones of the T91/T22 weldment. International Journal of Surface Engineering \& Materials Technology 4(2): 45-49.

6. Goyal, S., Laha, K., Chandravathi, K. S., and Rao, K. B. S. 2010. Prediction of type IV cracking behavior of $2.25 \mathrm{Cr}$ - 1 Mo steel weld joint based on finite element analysis. Transactions of the Indian Institute of Metals 63(2-3): 461-466. DOI: 10.1007/s12666-010-0065-2

7. Mas, F., Tassin, C., Valle, N., Robaut, F., Charlot, F., Yescas, M., Roch, F., Todeschini, P., and Brechet, Y. 2016. Metallurgical characterization of coupled carbon diffusion and precipitation in dissimilar steel welds. Journal of Materials Science 51: 4864-4879. DOI: $10.1007 / s 10853-016-9792-z$

8. Sudha, C., Paul, V. T., Terrance, A. L. E., Saroja, S., and Vijayalakshmi, M. 2006. Microstructure and microchemistry of hard zone in dissimilar weldments of $\mathrm{Cr}$-Mo steels. Welding Journal 85(4): 71-s to 80-s.

9. You, Y. Y., Shiue, R. K., Shiue, R. H., and Chen, C. 2001. The study of carbon migration in dissimilar welding of the modified 9Cr-1Mo steel. Journal of Materials Science Letters 20(15): 1429-1432. DOI: 10.1023/A:1011616232396

10. Strilkova, L., Kubon, Z., and Vodarek, V. 2010. Creep failure characteristics in P23/P91 dissimilar welds. Proc. $19^{\text {th }}$ Inter. Conf. of MATAL. Roznov pod Radhostem, Czech Republic, pp. 65-70.

11. Yamamoto, S. 2011. Arc welding of specific steels and cast irons. Tokyo, Japan, Kobe Steel, Ltd.

12. Anand, R., Sudha, C., Paul, V. T., Saroja, S., and Vijayalakshmi, M. 2010. Microstructural changes in grade 22 ferritic steel clad successively with Ni-based and $9 \mathrm{Cr}$ filler metals. Welding Journal 89(4): 65 -s to 74 -s.

13. Laha, K., Latha, S., Rao, K. B. S., Mannan, S. L., and Sastry, D. H. 2001. Comparison of creep behaviour of $2.25 \mathrm{Cr}-1 \mathrm{Mo} / 9 \mathrm{Cr}-$ 1Mo dissimilar weld joint with its base and weld metals. Materials Science and Technology 17: 1265-1272. DOI: 10.1179/ 026708301101509188

14. Sae-teaw, N., Poopat, B., Phung-on, I., and Chairuangsri, T. 2010. Analysis of microstructure in soft zone and precipitation zone of dissimilar Cr-Mo steels weldment. Asian International Journal of Science and Technology in Production and Manufacturing Engineering 3(2): 57-64.

15. Wu, Q., Lu, F., Cui, H., Liu, X., Wang, P., and Gao, Y. 2015. Soft zone formation by carbon migration and its effect on the high-cycle fatigue in $9 \% \mathrm{Cr}-\mathrm{CrMoV}$ dissimilar welded joint. Materials Letters 141: 242-244. DOI: 10.1016/j.matlet.2014.08.158

16. Petchsang, S., Phung-on, I., and Poopat, B. 2016. Life assessment for $\mathrm{Cr}$-Mo steel dissimilar joints by various filler metals using accelerated creep testing. Journal of Materials Engineering and Performance 25: 5424-5439. DOI: 10.1007/s11665-016-2386-8

17. Ehrlich, S. N., Hanson, J. C., Camara, A. L., Barrio, L., Estrella, M., Zhou, G., Si, R., Khalid, S., and Wang, Q. 2011. Combined XRD and XAS. Nuclear Instruments and Methods in Physics Research Section A: Accelerators, Spectrometers, Detectors and Associated Equipment 649: 213-215. DOI: 10.1016/j.nima. 2010.11.076

18. Sankar, G., Thomas, J. M., and Catlow, C. R. A. 2000. Combining $\mathrm{x}$-ray absorption with $\mathrm{x}$-ray diffraction for the structural elucidation of catalysts. Topics in Catalysis 10: 255-264. DOI: 10.1023/A:1019192824334

19. Klepka, M. T., Wolska, A., Lawniczak-Jablonska, K., Filipek, S. M., Sato, R., Paul-Boncour, V., and Marchuk, I. 2011. EXAFS and XRD investigation of crystal structure in $\mathrm{Cr}$ doped $\mathrm{YMn}_{2}$ deuterides. Radiation Physics and Chemistry 80 (10): 1019-1025. DOI: 10.1016/j.radphyschem.2011.03.016

20. Yingjie, L., Huliyageqi, B., Haschaolu, W., Song, Z., Tegus, O., and Nakai, I. 2014. EXAFS study of $\mathrm{Mn}_{1.28} \mathrm{Fe}_{0.67} \mathrm{P}_{0.46} \mathrm{Si}_{0.54}$ compound with first-order phase transition. Journal of Electron Spectroscopy and Related Phenomena 196: 104-109. DOI: 10.1016/j.elspec.2013.12.006 
21. Bugaev, A. L., Gudaa, A. A., Lazzarini, A., Lomachenko, K. A., Groppo, E., Pellegrini, R., Piovano, A., Emerich, H., Soldatov, A. V., Bugaev, L. A., Dmitrieva, V. P., Bokhoven, J. A. V., and Lamberti, C. 2017. In situ formation of hydrides and carbides in palladium catalyst: when XANES is better than EXAFS and XRD. Catalysis Today 283: 119-126. DOI: 10.1016/j.cattod.2016.02.065

22. Chubar, N., Gerda, V., Banerjee, D., and Yablokova, G. 2017. Effect of $\mathrm{Fe}$ (II)/Ce(III) dosage ratio on the structure and anion adsorptive removal of hydrothermally precipitated composites: insights from EXAFS/XANES, XRD and FTIR. Journal of Colloid and Interface Science 487: 388-400. DOI: 10.1016/j.jcis.2016.10.060

23. Lee, I. J., Park, J., Sung, N. E., and Kim, J. 2018. X-ray absorption fine structure investigation of the local structure of $\mathrm{SnO}_{2}$ doped ZnO films. Materials Chemistry and Physics 206: 103-109. DOI: 10.1016/j.matchemphys.2017.12.004

24. Andrini, L., Toja, R. M., Gauna, M. R., Conconi, M. S., Requejo, F. G., and Rendtorff, N. M. 2017. Extended and local structural characterization of a natural and $800^{\circ} \mathrm{C}$ fired $\mathrm{Na}$-montmorillonite-Patagonian bentonite by XRD and Al/Si XANES. Applied Clay Science 137: 233-240. DOI: 10.1016/j.clay.2016.12.030

25. ASME SA-213/SA-213M. 2015. Specification for Seamless Ferritic and Austenitic Alloy-Steel Boiler, Superheater, and Heat-Exchanger Tubes. New York, N.Y.: The American Society of Mechanical Engineers.

26. ASME SFA-5.28. 2015. Specification for Low-Alloy Steel Elec trodes and Rods for Gas Shielded Arc Welding. New York, N.Y.: The American Society of Mechanical Engineers.

27. ASTM International. 2007. ASTM E 407-07, Standard practice for microetching metals and alloys. West Conshohocken, $\mathrm{Pa}$.: ASTM International.

28. Klysubun, W., Kidkhunthod, P., Tarawarakarn, P., Sombunchoo, P., Kongmark, C., Limpijumnong, S., Rujirawat, S., Yimnirun, R., Tumcharern, G., and Faungnawakij, K. 2017. SUT-NANOTEC-SLRI beamline for x-ray absorption spectroscopy. Journal of Synchrotron Radiation 24: 707-716. DOI: 10.1107/ S1600577517004830

29. Kidkhunthod, P. 2017. Structural studies of advanced functional materials by synchrotron-based x-ray absorption spectroscopy: BL5.2 at SLRI, Thailand. Advances in Natural Sciences: Nanoscience and Nanotechnology 8(3): 1-6. DOI: 10.1088/2043-6254/aa7240

30. Newville, M. 2001. EXAFS analysis using FEFF and FEFFIT. Journal of Synchrotron Radiation 8: 96-100. DOI: 10.1107/ S0909049500016290

31. Ravel, B., and Newville, M. 2005. ATHENA, ARTEMIS, HEPHAESTUS: Data analysis for $\mathrm{x}$-ray absorption spectroscopy using IFEFFIT. Journal of Synchrotron Radiation 12: 537-541. DOI: 10.1107/S0909049505012719

32. Shtansky, D. V., Nakai, K., and Ohmori, Y. 2000. Decomposition of martensite by discontinuous-like precipitation reaction in an Fe-17Cr-0.5C alloy. Acta Materialia 48: 969-983. DOI: 10.1016/S1359-6454(99)00364-X

33. Pereloma, E. V., Miller, M. K., and Timokhina, I. B. 2008. On the decomposition of martensite during bake hardening of thermomechanically processed transformation-induced plasticity steels. Metallurgical and Materials Transactions A 39(13): 3210-3216. DOI: 10.1007/s11661-008-9663-6

34. Cheng, L., Brakman, C. M., Korevaar, B. M., and Mittemeijer, E. J. 1988. The tempering of iron-carbon martensite; dilatometric and calorimetric analysis. Metallurgical Transactions A 19(10): 2415-2426. DOI: 10.1007/BF02645469

35. Taxak, M., Kumar, S., Krishnamurthy, N., Suri, A. K., and Tiwari, G. P. 2012. Change in lattice parameter of tantalum due to dissolved hydrogen. Processing and Application of Ceramics 6(2): 73-76. DOI: 10.2298/PAC1202073T

36. Callister, W. D., and Rethwisch, D. G. 2014. Materials Science and Engineering: An Introduction, $9^{\text {th }}$ edition. Hoboken, N.J.: John Wiley \& Sons Inc.
37. Cheary, R. W., and Ma-Sorrell, Y. 2000. Quantitative phase analysis by $\mathrm{x}$-ray diffraction of martensite and austenite in strongly oriented orthodontic stainless steel wires. Journal of Materials Sciences 35: 1105-1113. DOI: 10.1023/A:1004755514188

38. Alves, J. M., Brandao, L. P., and Paula, A. S. 2015. The influence of sample preparation on the quantitative analysis of the volume fraction of martensite formed in a 304L trip steel. Materials Research 18: 159-163. DOI: 10.1590/1516-1439.347714

39. Zhang, P., Chen, Y., Xiao, W., Ping, D., and Zhao, X. 2016. Twin structure of the lath martensite in low carbon steel. Progress in Natural Science: Materials International 26: 169-172. DOI: 10.1016/j.pnsc.2016.03.004

40. Silwal, B., Li, L., Deceuster, A., and Graffiths, B. 2013. Effect of postweld heat treatment on the toughness of heat-affected zone for grade 91 steel. Welding Journal 92(3): 80-s to 87-s.

41. Baltusnikas, A., and Levinskas, R. 2006. XRD analysis of carbide phase in heat resistant steels. Materials Science 12(3): 192-198.

42. Lu, Y., Yu, H., and Sisson Jr., R. D. 2017. The effect of carbon content on the c/a ratio of as-quenched martensite in Fe-C alloys. Materials Science \& Engineering A 700: 592-597. DOI: 10.1016/j.msea.2017.05.094

43. Liu, T. W., Ping, D. H., Ohmura, T., and Ohnuma, M. 2018. Electron diffraction analysis of quenched $\mathrm{Fe}-\mathrm{C}$ martensite. Journal of Materials Sciences 53: 2976-2984. DOI: 10.1007/s10853-017-1731-0

44. Sherby, O. D.,Wadsworth, J., Lesuer, D. R., and Syn, C. K. 2007. The $\mathrm{c} / \mathrm{a}$ ratio in quenched $\mathrm{Fe}-\mathrm{C}$ and $\mathrm{Fe}-\mathrm{N}$ steels - a heuristic story. Materials Science Forum 539-543: 215-222. DOI:

10.4028/www.scientific.net/MSF.539-543.215

45. Sherby, O. D.,Wadsworth, J., Lesuer, D. R., and Syn, C. K. 2007. Revisiting the structure of martensite in iron-carbon steels. Materials Transactions 49(9): 2016-2027. DOI: 10.2320/matertrans.MRA2007338

46. Hutchinson, B., Hagstrom, J., Karlssson, O., Kindell, D., Tornberg, M., Lindberg, F., and Thuvander, M. 2011. Microstructures and hardness of as-quenched martensite (0.1-0.5\%C). Acta Materialia 59: 5845-5858. DOI: 10.1016/j.actamat.2011.05.061

47. Mythili, R., Saroja, S., Vijayalakshmi, M., and Rao, M. 2009. Study of strain induced martensite formation a Ti modified 316 stainless steel bellow by transmission electron microscopy. Transactions of the Indian Institute of Metals 62(6): 573-579. DOI:

10.1007/s12666-009-0096-8

48. Swanson, et al. 1955. Natl. Bur. Stand. (U.S.). Circ. 539, IV, 3.

49. Su, Y. Y., Chiu, L. H., Chen, F. S., Lin, S. C., and Pan, Y. T. 2014. Residual stress and dimensional changes related to the lattice parameter changes of heat-treated JIS SKD 11 tool steels. Materials Transactions 55(5): 831-837. DOI: 10.2320/matertrans.M2014031.

50. Ghoshal, S. K., and Dattagupta, S. 1998. 3-D model for strain ordering in steel: I Static effects. Pramana-Journal of Physics 51: 519-537. DOI: 10.1007/BF02828944

51. Mayr, P., Palmer, T. A., Elmer, J. W., Specht, E. D., and Allen, S. M. 2010. Formation of delta ferrite in $9 \mathrm{WtPct} C r$ steel investigated by in-situ x-ray diffraction using synchroton radiation. Metallurgical and Materials Transactions A 41(10): 2462-2465. DOI: 10.1007/s11661-010-03717.

SALITA PETCHSANG (psalita@eng.psu.ac.th) is with the Department of Mining and Materials Engineering, Prince of Songkla University, Songkhla, Thailand. ISARATAT PHUNG-ON is with the Maintenance Technology Center, ISTRS, King Mongkut's University of Technology, Bangkok, Thailand. JONGKOL SRITHORN is with the Department of Industrial Engineering, Suranaree University of Technology, Nakhon Ratchasima, Thailand. PINIT KIDKHUNTHOD is with the Synchrotron Light Research Institute, Nakhon Ratchasima, Thailand. 